\title{
Lipid composition of seed oils of different pomegranate (Punica granatum L.) cultivars from Spain
}

\author{
Luana Fernandes ${ }^{\mathrm{a}}$, José A. Pereira ${ }^{\mathrm{a}}$, Isabel Lopéz-Cortés ${ }^{\mathrm{b}}$, Domingo M. \\ SAlazar $^{\mathrm{b}}$, Elsa Ramalhosa ${ }^{\mathrm{a}^{*}}$, AND SUSANa CASAL ${ }^{\mathrm{c}}$ \\ ${ }^{a}$ Mountain Research Centre (CIMO) - School of Agriculture, Polytechnic Institute of Bragança, Campus de \\ $\mathrm{St}^{\mathrm{a}}$ Apolónia, Apartado 1172, 5301-855 Bragança, Portugal \\ b Departamento de Producción Vegetal. Universidad Politécnica de Valencia. Camino de Vera s/n, 46022 \\ Valencia, Spain \\ ${ }^{c}$ REQUIMTE/Laboratory of Bromatology and Hydrology, Faculty of Pharmacy, Porto University, Rua Jorge \\ Viterbo Ferreira, 228, 4050-313 Porto, Portugal \\ ${ }^{*}$ Corresponding author \\ elsa@ipb.pt \\ TEL: +351-273303308 \\ FAX: $+351-273325405$
}

Received: 30 June 2014; Published online: 18 April 2015

Invited paper from the International Food Congress - Novel Approaches in Food Industry - NAFI 2014

\begin{abstract}
Pomegranate (Punica granatum L.) is an ancient fruit tree traditionally cultivated in the Near and Middle East. Presently, its most important growing regions include Afghanistan, Iran, Israel, USA, Italy and Spain, the latter country the largest European exporter. The pomegranate fruit can be divided into several anatomical compartments: outside peel, inside peel, and arils (pulp and seeds), the last part being usually used for consumption as is or for juice, jams and jellies production. Even though pomegranate seeds are an industrial by-product, recent reports have highlighted their potential use as a source of oil with beneficial chemical attributes. Therefore, the main objective of the present work was to characterize the seed oil of nine European pomegranate varieties, collected in Spain, for their fatty acid and vitamin E compositions. All seed lipid fractions consisted mainly of punicic acid (c9,t11,c13 C-18:3), ranging between $77.3 \%$ and $83.6 \%$ of total fatty acids, followed by small amounts of linoleic acid (C18:2n6), oleic acid (C18:1n9) and palmitic acid (C16:0). Regarding vitamin E composition, $\alpha-, \gamma-, \delta$-tocopherols were found in all pomegranate seed oils, but mainly $\gamma$-tocopherol, with total tocopherols ranging from 174.5 to $627.3 \mathrm{mg} / 100 \mathrm{~g}$ oil.

The richness of these pomegranate varieties seed oils in punicic acid, a conjugated linolenic acid with interesting anti-carcinogenic activity, and the elevated amount of tocopherols on the extracted lipids, of technological and nutritional relevance, make this by-product interesting for further exploitation.
\end{abstract}

Keywords: Pomegranate; Seed oils; Fatty acids; Tocopherols; Spain.

\section{Introduction}

Pomegranate (Punica granatum L.) is mainly consumed fresh; however, it has been used in the preparation of juices, jams, etc. (Goula \& Adamopoulos, 2012). The arils, the juicier part, represent from $50 \%$ to $70 \%$ of the fruit mass but include an inner woody part, the seed, representing from 5 to $15 \%$ (Eikani, Golmohammad, \& Homami, 2012), which are usually disposed of as waste material in many pomegranate-processing industries. Pomegranate seeds are richer in fibre 
and fat (Eikani et al., 2012; Hernández, Melgarejo, Martínez, Martínez, \& Legua, 2011), than in other beneficial phytochemicals. From economic and environment points of view, disposing of such waste should be avoided (Pande \& Akoh, 2009).

Several studies have shown that pomegranate seed oils present interesting properties due to their elevated content of unsaturated fatty acids, particularly conjugated ones. These fatty acids play a natural preventive role in cardiovascular diseases, mainly because they promote reduction of total cholesterol (Melgarejo \& Artés, 2000), but other health attributes are being increasingly reported, including anti-carcinogenic activity (Kohno et al., 2004). Several studies have been performed on fatty acid composition in Iranian (Fadavi, Barzegar, \& Azizi, 2006; Habibnia, Ghavami, Ansaripourc, \& Vosough, 2012), Turkish (Kýralan, Golukcu, \& Tokgoz, 2009), Tunisian and Chinese (Elfalleh, Ying, et al., 2011; Jing et al., 2012) cultivars. Still, few studies have been performed on European cultivars (Melgarejo \& Artés, 2000; Hernández et al., 2011). Moreover, some pomegranate seed oils have shown interesting tocopherol contents (Caligiani, Bonzanini, Palla, Cirlini, \& Bruni, 2010; Habibnia et al., 2012; Jing et al., 2012), recognized for their antioxidant activity, particularly important in the prevention of lipid oxidation processes.

The aim of the present work was to analyze nine pomegranate cultivars produced in Spain in terms of their lipid profile.

\section{Materials and Methods}

\subsection{Sampling and extraction of seed oils}

Nine cultivars harvested in Valencia (Spain), in the crop season of 2013, were selected, namely: CG8, Cis 127, Mollar de Elche, Parfianka, Katirbasi, Valenciana, White, Wonderful 1 and Wonderful 2 (Figure 1). All of them were collected when fully ripe. For each variety, 15 grams of seeds were crushed in a mortar with a pestle, and dehydrated by addition of anhydrous sodium sulphate. The lipids were extracted in a Soxhlet device with petroleum ether (with $0.01 \%$ BHT - 2,6-di-tert-butyl-4-methylphenol) for a $4 \mathrm{~h}$ period, in triplicate for each cultivar.

\section{$2.2 \quad$ Fatty acids}

Fatty acid methyl esters were obtained by transesterification with methanolic potassium hydroxide 2M. Fatty acids were determined by gas chromatography (Chrompack, CP-9001 model, The Netherlands) with flame ionization detection (GC-FID). The gas chromatograph was equipped with a split/splitless injector system and an autosampler (Chrompack CP-9050 model). Fatty acid separation was carried out on a CP-Sil 88 column $(50 \mathrm{~m} \times 0.25 \mathrm{~mm} \times 0.19 \mu \mathrm{m}$; Varian $)$. Helium was used as carrier gas at a pressure of $120 \mathrm{kPa}$. The temperatures of the injector and detector were $250{ }^{\circ} \mathrm{C}$ and $270{ }^{\circ} \mathrm{C}$, respectively. The separation of the methyl esters was carried out with a temperature gradient between 180 and $220{ }^{\circ} \mathrm{C}$. The identification of the chromatographic peaks was performed by comparing the retention time of the sample with a mixture of several standards from diverse producers $(\mathrm{Su}-$ pelco - USA, Nu-Chek - USA and Larodan Sweeden) and by comparison with literature data on pomegranate seed oils (Melgarejo \& Artés, 2000; Pande \& Akoh, 2009; Elfalleh, Ying, et al., 2011) . For quantification of total fatty acid content in the oil, an internal standard (triundecanoin) was used.

\section{$2.3 \quad$ Vitamin E}

An accurate amount of oil was weighed, the internal standard added (tocol purchased from Matreya, USA), dissolved in $n$-hexane, centrifuged at $13,000 \mathrm{rpm}$ and transferred to the injection vials. An HPLC chromatograph (Jasco) equipped with a pump (PU-980 model), mixing chamber (HG 980-30) and an autosampler (AS2057 Plus model) was used for tocochromanol separation. Detection was performed by fluorescence (FP2020 Plus model at $290 \mathrm{~nm}$ (excitation) and $330 \mathrm{~nm}$ (emission) wavelengths). The separation of tocopherols $(\alpha, \beta, \gamma, \delta)$ and tocotrienols $(\alpha, \beta, \gamma, \delta)$ was performed on a normal phase silica Supelcosil LC-SI (Supelco) col- 
Pomegranate seed oils $\mid 97$

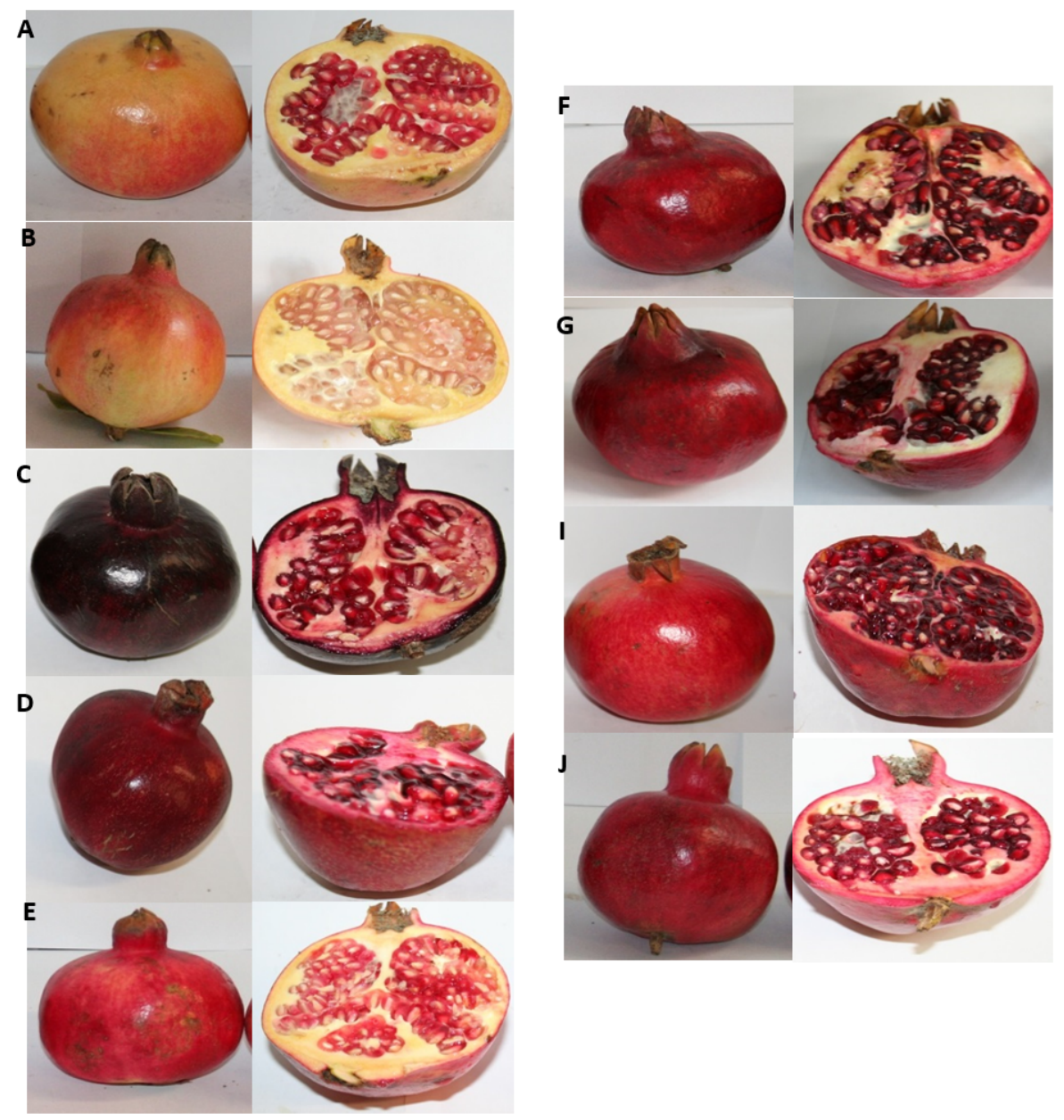

Figure 1: The nine pomegranate cultivars studied in the present work: A - Mollar de Elche, B - Valenciana, C - White, D - CG8, E - Cis 127, F - Katirbasi, G - Parfianka, H - Wonderful 1, and I - Wonderful 2 
98 | Fernandes et al.

umn $(150 \mathrm{~mm} \times 3.0 \mathrm{~mm} \times 3 \mu \mathrm{m})$, using hexane:dioxane $(97: 3 \mathrm{v} / \mathrm{v})$ mixture as eluent $(0.7$ $\mathrm{mL} / \mathrm{min}$ ) at ambient temperature. The quantification was performed using the internal standard method. Standard solutions of tocopherols and tocotrienols were graded according to their molar absorptivity.

\section{$2.4 \quad$ Statistical analysis}

The statistical software SPSS, version 18.0 (SPSS Inc., Chicago, IL), was used for the statistical treatment of the data. The influence of the cultivar over fatty acid and vitamin E compositions was evaluated using the one-way analysis of variance (one-way ANOVA) $(\mathrm{p}<0.05)$, followed by the Tukey's HSD post hoc test, when variances of the groups were identical. On the other hand, when variances were not identical, the GamesHowell's test coupled with Welch's statistic was applied. The variance homogeneity was evaluated by the Levene's test.

A Principal Component Analysis (PCA) was also performed for the results for the fatty acids and tocopherols of the pomegranate cultivars. The PCA score plot was used to differentiate pomegranate cultivars through their chemical compositions.

\section{Results and Discussion}

\subsection{Fatty Acid Composition}

The total lipid content and fatty acid composition of pomegranate seed oils are given in Table 1 and Figure 2 . The total lipids ranged between 4.44 - 13.70\% for Valenciana and Katirbasi cultivars, respectively. This range was in agreement with Melgarejo and Artés (2000), with 6.2 to $12.2 \%$ for the Piñón Tierno de Ojos - PTO4 and Piñonenca de Blanca - PB1 varieties, respectively. Moreover, our maximums were identical to those found by Jing et al. (2012) for the Suanshiliu and Sanbaitian varieties of 11.4 and $14.8 \%$, respectively. On contrary, our results were lower than Pande and Akoh (2009) who obtained values between $18.1 \%$ and $21.5 \%$ for the R19 and North varieties, respectively, Elfalleh, Ying, et al. (2011) who found 5.98\% (Mezzi 2) to $21.58 \%$ (Rafrafi), Kýralan et al. (2009) who found $13.95 \%$ (Eksilik) to $24.13 \%$ (Fellahyemez), and Fadavi et al. (2006) who found 6.6\% (Syah) to $19.3 \%$ (Syahdane Shahvar Kan). Fifteen fatty acids were detected but only ten were identified. The individual percentages of the four major fatty acids are represented in Figure 2. The extracted oils were mainly unsaturated (ca. 91.8 to $94.2 \%$ ). Nevertheless, our range was smaller than that reported by Melgarejo and Artés (2000) of 73.35 to $95.84 \%$, indicative of a greater consistency between samples. Punicic acid, a geometric isomer of linolenic acid, was the predominant fatty acid in all pomegranate cultivars. Its amount ranged between 77.3 to $83.6 \%$ for Parfianka and Wonderful 2 cultivars, respectively. Linoleic acid and oleic acid were the following most abundant fatty acids in these samples. Their amounts ranged between 3.9 to 5.4 $\%$ (Katirbasi and White cultivars, respectively) and 3.1 to $5.7 \%$ (White and Wonderful 1, respectively). Our results were in agreement with the literature. Qualitatively, our fatty acid composition was similar to previous findings (Pande \& Akoh, 2009; Hernández et al., 2011; Jing et al., 2012; Kýralan et al., 2009; Fadavi et al., 2006; Eikani et al., 2012; Elfalleh, Ying, et al., 2011; Liu, Xu, Gong, He, \& Gao, 2012; Liu, Xu, Hao, \& Gao, 2009). Regarding the monounsaturated fatty acids (MUFA), oleic acid was the predominant one in pomegranate seed oils and accounted 3.1 to $5.7 \%$ of total fatty acids for the White and Wonderful 1 cultivars, respectively. The total saturated fatty acids (SFA) of pomegranate seed oils ranged from 4.9 to $7.3 \%$ for Cis 127 and Valenciana cultivars, respectively. The SFA consisted mainly of palmitic acid (3.1 to $4.0 \%$ ). The Mollar de Elche cultivar contained the highest amount of this fatty acid, with Katirbasi and CG8 cultivars having the least amounts. The unsaturated/saturated acid ratio was generally very high, varying between 12.6 (Valenciana cultivar) and 19.2 (Cis 127 cultivar). This range was narrower than that reported by Fadavi et al. (2006) (2.70-20.0), but similar to that presented by Hernández et al. (2011) for sweet cultivars (13.0-17.5).

Concerning the percentages of fatty acids that were not identified in each cultivar, these were 6.2\% (Mollar de Elche), 3.4\% (Valenciana), 1.4\% 
Pomegranate seed oils $\mid 99$

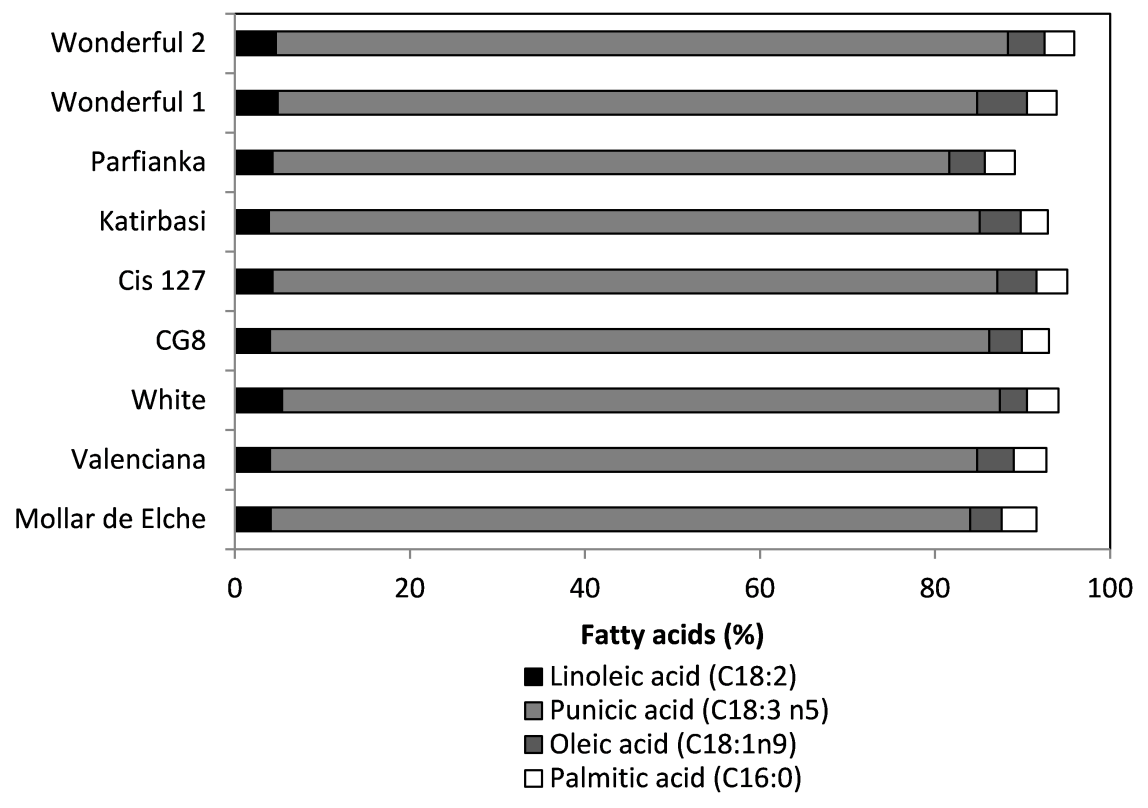

Figure 2: The four most abundant fatty acids (\%) in the seed oils extracted from nine pomegranate cultivars

Table 1: Total oil content, total SFA, MUFA and PUFA (\%) of the seed oils extracted from nine pomegranate cultivars

\begin{tabular}{lcccccc}
\hline \multicolumn{1}{c}{ Cultivars } & $\begin{array}{c}\text { Total Oil } \\
\text { content } \\
(\%)\end{array}$ & $\begin{array}{c}\text { Total } \\
\text { SFA } \\
(\%)\end{array}$ & $\begin{array}{c}\text { Total } \\
\text { MUFA } \\
(\boldsymbol{\%})\end{array}$ & $\begin{array}{c}\text { Total } \\
\text { PUFA } \\
(\boldsymbol{\%})\end{array}$ & $\begin{array}{c}\text { Total } \\
\text { Unsat } \\
(\boldsymbol{\%})\end{array}$ & $\begin{array}{c}\text { (PUFA+ } \\
\text { MUFA) } \\
\text { /SFA }\end{array}$ \\
\hline Mollar de Elche & $5.33 \pm 2.08^{a}$ & 5.6 & 3.7 & 89.5 & 93.2 & 16.6 \\
Valenciana & $4.44 \pm 1.77^{a}$ & 7.3 & 4.2 & 87.6 & 91.8 & 12.6 \\
White & $5.42 \pm 1.62^{a}$ & 7.0 & 3.9 & 89.1 & 93.0 & 13.3 \\
CG8 & $12.04 \pm 3.43^{b, c}$ & 6.1 & 4.3 & 88.5 & 92.8 & 15.2 \\
Cis 127 & $5.94 \pm 0.95^{a, b}$ & 4.9 & 4.5 & 89.7 & 94.2 & 19.2 \\
Katirbasi & $13.70 \pm 1.42^{c}$ & 6.5 & 5.2 & 87.4 & 92.6 & 14.2 \\
Parfianka & $5.97 \pm 0.88^{a, b}$ & 6.5 & 4.5 & 87.9 & 92.4 & 14.2 \\
Wonderful 1 & $8.60 \pm 3.15^{a, b, c}$ & 6.6 & 6.3 & 86.2 & 92.5 & 14.0 \\
Wonderful 2 & $6.85 \pm 2.48^{a, b, c}$ & 6.6 & 4.8 & 88.9 & 93.7 & 14.2 \\
\hline
\end{tabular}


(White), 3.1\% (CG8), 3.2\% (Cis 127), 2.8\% (Katirbasi), $7.1 \%$ (Parfianka), 1.8\% (Wonderful 1) and $0.3 \%$ (Wonderful 2). Quantitatively, fatty acid compositions were statistically different $(\mathrm{p}<0.05)$ depending on the cultivar.

\subsection{Tocopherols and Tocotrienols}

In the pomegranate cultivars investigated, the tocopherols identified were $\alpha$-, $\gamma$ - and $\delta$-tocopherol, while $\beta$-tocopherol and tocotrienols were not detected. The total amount of tocopherols varied from 174.5 to $627.3 \mathrm{mg} / 100 \mathrm{~g}$ of extracted oil for the White and Katirbasi cultivars, with a mean value of $445.4 \mathrm{mg} / 100 \mathrm{~g}$ of oil (Figure 3). The predominant tocopherol was $\gamma$-tocopherol, with contents ranging from 159.7 and $586.2 \mathrm{mg} / 100 \mathrm{~g}$ for the White and Katirbasi cultivars, respectively, and a mean value of $416.7 \mathrm{mg} / 100 \mathrm{~g}(93.5 \%) . \alpha$ tocopherol concentration varied between 8.9 and $26.1 \mathrm{mg} / 100 \mathrm{~g}$ of oil for White and Katirbasi cultivars, respectively, with a mean value of 16.6 $\mathrm{mg} / 100 \mathrm{~g}$ of oil ( $3.7 \%$ of total tocopherols). $\delta$ tocopherol was found in slight lower amounts, varying between 6.0 and $15.2 \mathrm{mg} / 100 \mathrm{~g}$ of oil for the White and Parfianka cultivars, respectively, with a mean value of $12.2 \mathrm{mg} / 100 \mathrm{~g}$ of oil ( $2.7 \%$ of total tocopherols). Moreover, the contents of tocopherols differed significantly between cultivars. Cultivar Katirbasi had the highest levels of total tocopherols, $\alpha$ - and $\gamma$-tocopherol. The content of $\delta$-tocopherol in the Katirbasi cultivar did not differ from that in Parfianka cultivar which had the highest $\delta$-tocopherol level among the cultivars investigated.

Our $\gamma$-tocopherol contents (159.7 to 586.2 $\mathrm{mg} / 100 \mathrm{~g}$ of oil) were similar to those described by Liu et al. (2012), whose values varied between 120.62 and $672.56 \mathrm{mg} / 100 \mathrm{~g}$ oil. On the other hand, our $\alpha$-tocopherol values (13.0 to 20.6 $\mathrm{mg} / 100 \mathrm{~g}$ ) were lower than those obtained by Pande and Akoh (2009) (between 161.2 and 173.7 $\mathrm{mg} / 100 \mathrm{~g})$. In the present work the following order was found: $\gamma$-tocopherol $>\alpha$-tocopherol $>\delta$ tocopherol; this was different to that reported by Jing et al. (2012) ( $\delta$-tocopherol $>\alpha$-tocopherol $>$ $\gamma$-tocopherol) and Elfalleh, Tlili, et al. (2011) $(\alpha$ tocopherol $>\gamma$-tocopherol $>\delta$-tocopherol). Furthermore, in the present work $\beta$-tocopherol was not detected unlike Caligiani et al. (2010), who found high amounts of this compound in all the samples analyzed. These differences might be a consequence of the chromatographic separation mode used, in our particular case normal-phase, enabling full separation of all tocopherols and tocotrienols compounds.

\subsection{Principal Component Analysis}

PCA was done to differentiate the nine pomegranate cultivars using fatty acid and tocopherol contents. From this analysis, two PCs were obtained: PC 1 (60.6\%) and PC 2 (35.0\%), which together accounted for $95.6 \%$ of the variance. PC 1 associated positively to $\delta$-, $\gamma$ - and $\alpha$-tocopherol, as well as MUFA. PC 2 associated positively to SFA and negatively to PUFA. Figure 4 shows that pomegranate cultivars appeared to be clustered between three groups. The White cultivar, as well as Mollar de Elche and Cis 127 cultivars, were individualized, forming the first and second group, respectively. All the rest cultivars were grouped together (third group). The White cultivar presented one of the lowest tocopherol and MUFA contents. The second group contained Mollar de Elche and Cis 127 cultivars, both having the highest PUFA and the lowest SFA contents. These characteristics seemed to be responsible for the absence of a close relation to other cultivars.

\section{Conclusions}

Pomegranate seed oils had very high levels of unsaturated fatty acids, being very rich in punicic acid. This compound has been shown to be protective against some cancer types, making pomegranate seed commercialization a possible way to add value to this by-product. Cis 127 was the cultivar that presented the highest unsaturated fatty acid content, closely followed by Mollar de Elche and Wonderful 2 cultivars. Nevertheless, the last cultivar was the one that presented the highest percentage of punicic acid. Regarding tocopherols, pomegranate seed oils are a good source of $\gamma$-tocopherol, although containing other tocopherols in minor amounts. The White cultivar presented the lowest tocopherol 
Pomegranate seed oils |101

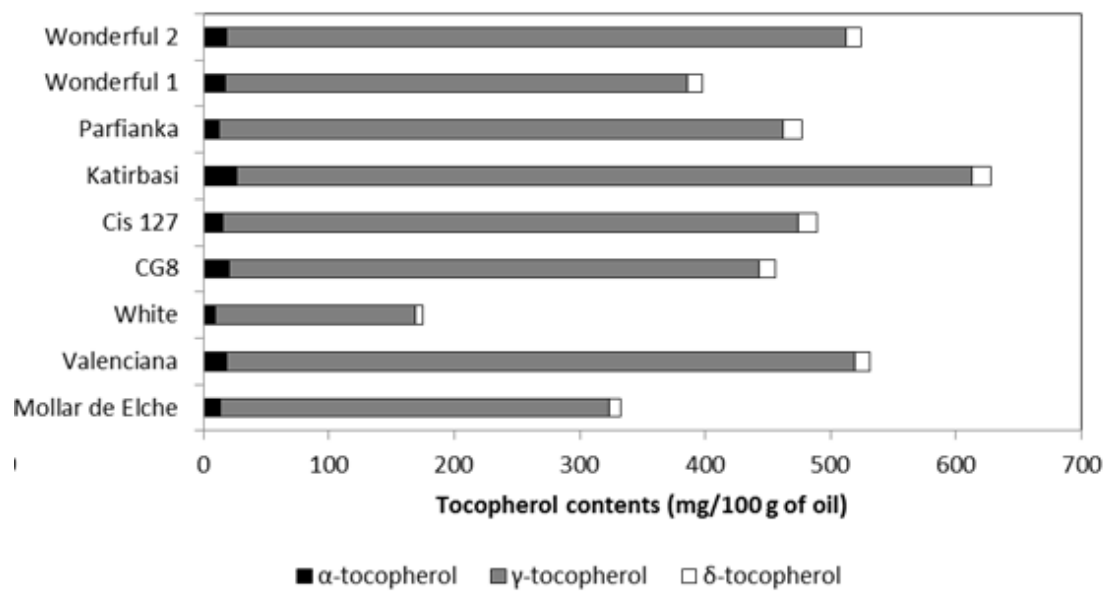

Figure 3: Tocopherol profile of pomegranate seed oils (mg/100g of oil)

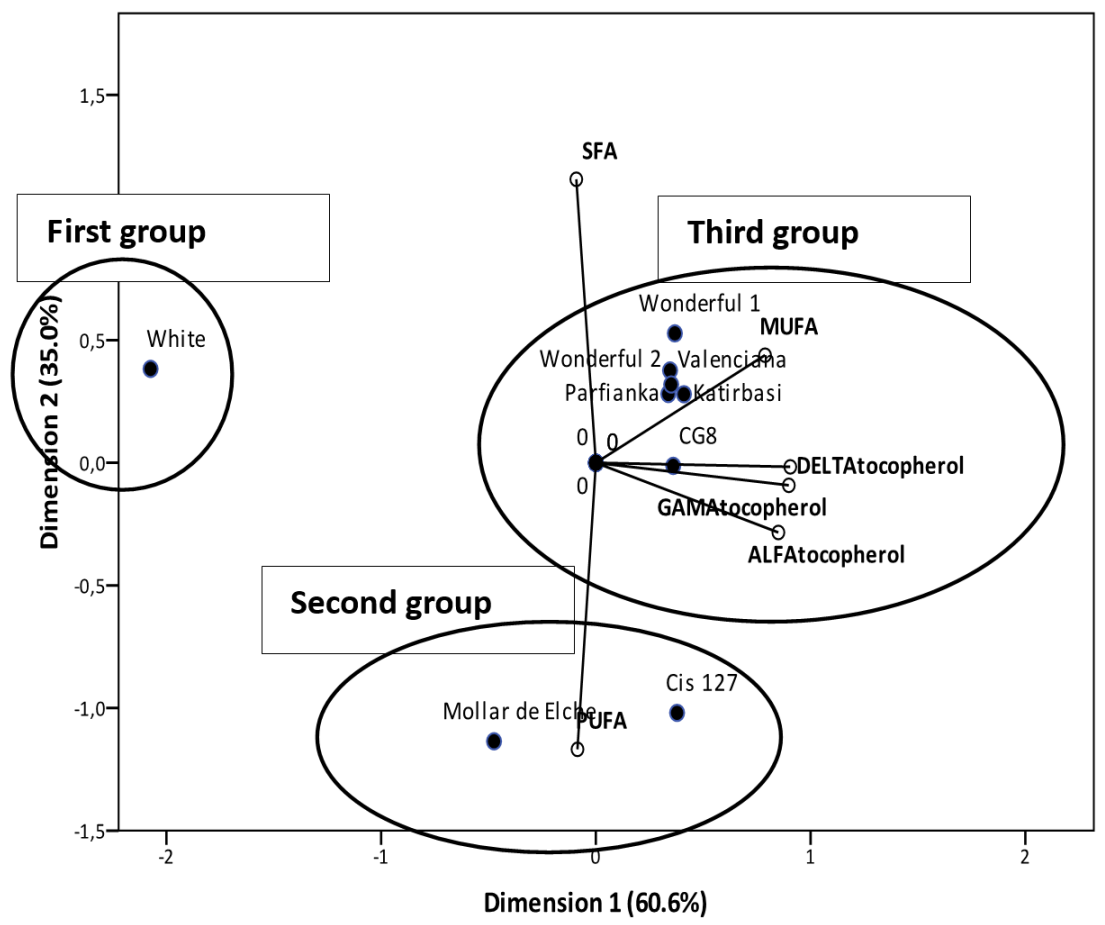

Figure 4: Principal component analysis plot of data from fatty acid and tocopherols of nine pomegranate cultivars 
content. When applying PCA to the fatty acids and tocopherols composition, significant variability between some of pomegranate cultivars was found. These components could be used for a better population profiling. Moreover, the differences found on tocopherols content show that it is possible to increase the levels of healthy compounds by the appropriate choice of cultivars. Advanced plant breeding could further improve the plant material and produce superior cultivars for use, e.g., in the fortification of pomegranate juices. In summary, this study provided valuable information for the cultivar selection and for developing value-added utilization of pomegranate seeds or seed fractions, such as oil, as nutraceuticals or functional food ingredients.

\section{Acknowledgements}

Authors are grateful to POCTEP - Programa de Cooperação Transfronteiriça Espanha - Portugal for financial support through the Project "RED/AGROTEC - Experimentation network and transfer for development of agricultural and agro industrial sectors between Spain and Portugal". The authors are also grateful to strategic projects PEst-OE/AGR/UI0690/2011 and PEstC/EQB/LA0006/2013 for financial support to CIMO and REQUIMTE, respectively.

\section{References}

Caligiani, A., Bonzanini, F., Palla, G., Cirlini, M., \& Bruni, R. (2010). Characterization of a potential nutraceutical ingredient: pomegranate (punica granatum l.) seed oil unsaponifiable fraction. Plant Foods for Human Nutrition, 65(3), 277-283. doi:10. 1007/s11130-010-0173-5

Eikani, M. H., Golmohammad, F., \& Homami, S. S. (2012). Extraction of pomegranate (Punica granatum L.) seed oil using superheated hexane. Food and Bioproducts Processing, 90(1), 32-36. doi:10.1016/j.fbp. 2011.01.002

Elfalleh, W., Tlili, N., Nasri, N., Yahia, Y., Hannachi, H., Chaira, N., ... Ferchichi, A. (2011). Antioxidant capacities of phenolic compounds and tocopherols from tunisian pomegranate (Punica granatum L.) fruits. Journal of Food Science, 76(5), C707C713. doi:10.1111/j.1750-3841.2011.02179. $\mathrm{x}$

Elfalleh, W., Ying, M., Nasri, N., Sheng-Hua, H., Guasmi, F., \& Ferchichi, A. (2011). Fatty acids from tunisian and chinese pomegranate (Punica granatum L.) seeds. International Journal of Food Sciences and Nutrition, 62(3), 200-206. doi:10.3109/ 09637486.2010.526932

Fadavi, A., Barzegar, M., \& Azizi, M. H. (2006). Determination of fatty acids and total lipid content in oilseed of 25 pomegranates varieties grown in Iran. Journal of Food Composition and Analysis, 19(6-7), 676-680. doi:10.1016/j.jfca.2004.09.002

Goula, A. M. \& Adamopoulos, K. G. (2012). A method for pomegranate seed application in food industries: seed oil encapsulation. Food and Bioproducts Processing, 90(4), 639-652. doi:10.1016/j.fbp.2012.06.001

Habibnia, M., Ghavami, M., Ansaripourc, M., \& Vosough, S. (2012). Chemical evaluation of oils extracted from five different varieties of iranian pomegranate seeds. Journal of Food Biosciences and Technology, 2, 35-40.

Hernández, F., Melgarejo, P., Martínez, J. J., Martínez, R., \& Legua, P. (2011). Fatty acid composition of seed oils from important spanish pomegranate cultivars. Italian Journal of Food Science, 23(2), 188-193.

Jing, P., Ye, T., Shi, H., Sheng, Y., Slavin, M., Gao, B., ... Yu, L. ( (2012). Antioxidant properties and phytochemical composition of china-grown pomegranate seeds. Food Chemistry, 132(3), 1457-1464. doi:10. 1016/j.foodchem.2011.12.002

Kohno, H., Suzuki, R., Yasui, Y., Hosokawa, M., Miyashita, K., \& Tanaka, T. (2004). Pomegranate seed oil rich in conjugated linolenic acid suppresses chemically induced colon carcinogenesis in rats. Cancer Science, 95(6), 481-486. doi:10.1111/j. 1349-7006.2004.tb03236.x

Kýralan, M., Golukcu, M., \& Tokgoz, H. (2009). Oil and conjugated linolenic acid contents of seeds from important pomegranate cultivars (Punica granatum L.) grown in turkey. Journal of the American Oil Chemists' 
Pomegranate seed oils $\mid 103$

Society, 86(10), 985-990. doi:10.1007/ s11746-009-1436-X

Liu, G., Xu, X., Hao, Q., \& Gao, Y. (2009). Supercritical $\mathrm{CO} 2$ extraction optimization of pomegranate (Punica granatum L.) seed oil using response surface methodology. $L W T$ Food Science and Technology, 42(9), 14911495. doi:10.1016/j.lwt.2009.04.011

Liu, G., Xu, X., Gong, Y., He, L., \& Gao, Y. (2012). Effects of supercritical CO2 extraction parameters on chemical composition and free radical-scavenging activity of pomegranate (Punica granatum L.) seed oil. Food and Bioproducts Processing, 90 (3), 573-578. doi:10.1016/j.fbp.2011.11. 004

Melgarejo, P. \& Artés, F. (2000). Total lipid content and fatty acid composition of oilseed from lesser known sweet pomegranate clones. Journal of the Science of Food and Agriculture, 80 (10), 1452-1454. doi:10. 1002/1097-0010(200008)80:10<1452::AIDJSFA665>3.0.CO;2-L

Pande, G. \& Akoh, C. C. (2009). Antioxidant capacity and lipid characterization of six Georgia-grown pomegranate cultivars. Journal of Agricultural and Food Chemistry, 57(20), 9427-9436. doi:10 . 1021 / jf901880p 